\title{
Mutant (CCTG)n Expansion Causes Abnormal Expression of Zinc Finger Protein 9 (ZNF9) in Myotonic Dystrophy Type 2
}

\author{
Olayinka Raheem, ${ }^{*}$ Shodimu-Emmanuel Olufemi, ${ }^{\dagger}$ \\ Linda L. Bachinski, ${ }^{\dagger}$ Anna Vihola,${ }^{\ddagger}$ Mario Sirito, ${ }^{\dagger}$ \\ Jeanette Holmlund-Hampf, ${ }^{\ddagger}$ Hannu Haapasalo, ${ }^{\S}$ \\ Yi-Ping Li, ${ }^{\text {Tा }}$ Bjarne Udd, ${ }^{* \neq \|}$ and Ralf Krahe ${ }^{\dagger * * \dagger \dagger}$ \\ From the Neuromuscular Research Unit," University of Tampere \\ and Tampere University Hospital, Tampere, Finland; the \\ Department of Genetics, ${ }^{\dagger}$ University of Texas MD Anderson \\ Cancer Center, Houston, Texas; Folkhälsan Institute of Genetics, ${ }^{\ddagger}$ \\ and the Department of Medical Genetics, University of Helsinki, \\ Helsinki, Finland; the Center for Laboratory Medicine, \\ Department of Pathology, Pirkanmaa Hospital District, Tampere, \\ Finland; the Department of Cytokine Biology, "The Forsyth \\ Institute and Harvard School of Dental Medicine, Boston, \\ Massachusetts; the Department of Neurology," Vaasa Central \\ Hospital, Vaasa, Finland; and the Graduate Programs in \\ Human and Molecular Genetics, ${ }^{* *}$ and Genes and Development, ${ }^{\text {H }}$ \\ University of Texas at Houston Graduate School of Biomedical \\ Sciences, Houston, Texas
}

The mutation that underlies myotonic dystrophy type 2 (DM2) is a (CCTG)n expansion in intron 1 of zinc finger protein 9 (ZNF9). It has been suggested that ZNF9 is of no consequence for disease pathogenesis. We determined the expression levels of ZNF9 during muscle cell differentiation and in DM2 muscle by microarray profiling, real-time RT-PCR, splice variant analysis, immunofluorescence, and Western blotting. Our results show that in differentiating myoblasts, ZNF9 protein was localized primarily to the nucleus, whereas in mature muscle fibers, it was cytoplasmic and organized in sarcomeric striations at the Z-disk. In patients with DM2, ZNF9 was abnormally expressed. First, there was an overall reduction in both the mRNA and protein levels. Second, the subcellular localization of the ZNF9 protein was somewhat less cytoplasmic and more membrane-bound. Third, our splice variant analysis revealed retention of intron 3 in an aberrant isoform, and fourth quantitative allelespecific expression analysis showed the persistence of intron 1 sequences from the abnormal allele, further suggesting that the mutant allele is incompletely spliced. Thus, the decrease in total expression appears to be due to impaired splicing of the mutant transcript. Our data indicate that ZNF9 expression in DM2 patients is altered at multiple levels. Although toxic RNA effects likely explain overlapping phenotypic manifestations between DM1 and DM2, abnormal ZNF9 levels in DM2 may account for the differences in DM1. (Am J Pathol 2010, 177:3025-3036; DOI: 10.2353/ajpath.2010.100179)

Myotonic dystrophy (Dystrophia myotonica; DM) is the most common inherited muscular dystrophy in adults. Both myotonic dystrophy type 1 (DM1; Steinert's disease [Online Mendelian Inheritance in Man (OMIM) number 160900]) and type 2 (DM2; Proximal Myotonic Myopathy (PROMM) [OMIM number 602668]) are dominantly inherited disorders with an estimated prevalence of 1/8000 in DM1. ${ }^{1}$ The prevalence of DM2 is not established, but estimated to be similar to DM1 in European populations. ${ }^{2}$ DM1 is caused by a (CTG) trinucleotide repeat expansion mutation in the $3^{\prime}$ untranslated region (UTR) of the dystrophia myotonica protein kinase gene in chromosome $19 q 13.3^{3-5}$ The mutation underlying DM2 is a tetranucleotide $(\mathrm{CCTG})_{\mathrm{n}}$ repeat expansion in intron 1 of the zinc finger protein 9 (ZNF9) gene, also known as cellular nucleic acid-binding protein, in chromosome $3 q 21 .{ }^{6,7}$ The pathogenic repeat size in patients with DM2 ranges from approximately 50 to $11,000 .^{6,8}$ In contrast to DM1 there

Supported by grants from NIH (R01 AR48171 to R.K.), Muscular Dystrophy Association USA, and the Kleberg Foundation; funding from the Folkhälsan Research Foundation (B.U.); and grants from the Liv\&Hälsa Foundation, the Vasa Central Hospital District Medical Research funds, Tampere University Hospital Medical Research funds.

O.R. and S.-E.O. contributed equally to this work.

Accepted for publication August 26, 2010.

Address reprint requests to Ralf Krahe, Ph.D., Department of Genetics, University of Texas MD Anderson Cancer Center, Houston, TX 77030. E-mail: rkrahe@mdanderson.org; or Olayinka Raheem, MSc, Neuromuscular Molecular Pathology, University of Tampere, Biokatu 10 Finn-Medi 3, 4-103, 33520 Tampere, Finland. E-mail: olayinka.raheem@uta.fi. 
appears to be no clear genotype/phenotype correlation between expansion size and disease severity in DM2. ${ }^{2}$

The major symptoms of DM2 include late-onset proximal muscle weakness, myalgic muscle pain and/or stiffness, cataracts, myotonia, tremors, cardiac conduction defects, and endocrinological abnormalities. ${ }^{2}$ However, compared with adult-onset DM1 clinical symptoms are more inconsistent and extremely diverse in DM2., ${ }^{2,9}$ In any given DM2 patient, any of these symptoms may be absent, and myotonia may be variable over time in the same individual. A number of less consistent findings are occasionally associated with this disorder, making the clinical diagnosis a challenge. 2,10 Histopathological features in DM1 and DM2 are also different. Ring fibers and sarcoplasmic masses are characteristic features only in DM1, whereas nuclear clump fibers are prominent in DM2 and are present even before clinical muscle weakness. ${ }^{1,11,12}$ In DM1, type 1 fiber atrophy may be present, whereas in DM2 a subpopulation of type 2 fibers, including the nuclear clump fibers, most of which are not detected by conventional ATPase staining, are extremely atrophic. ${ }^{11}$

The prevailing paradigm is that DM1 and DM2 are toxic RNA diseases: transcription of the repeats into mutant $(\mathrm{CUG})_{\mathrm{DM}_{1} 1} /(\mathrm{CCUG})_{\mathrm{DM}_{2}}$-containing RNAs is both necessary and sufficient to cause disease by formation of ribonuclear foci and interference of the splicing of downstream "effector" genes through trans-acting splicing factors, particularly CUG binding protein $1^{13}$ and muscleblind $1 .{ }^{14,15}$ For DM1 it has also been suggested that the pathogenic mechanism might be a dominant-negative mutation manifested at RNA level. ${ }^{16}$ Two studies_one using four immortalized lymphoblastoid cell lines, ${ }^{17}$ the other primary myoblast cultures from a heterozygous and a homozygous patient ${ }^{18}$ - showed no effect of the (CCTG) DM2 $_{2}$ expansion on ZNF9 mRNA and protein levels. ${ }^{17,18}$ However, heterozygous $Z n f 9^{+/-}$knockout mice developed a multiorgan phenotype resembling $\mathrm{DM},{ }^{19}$ and recently a growing number of studies showed that ZNF9 may not be normally expressed in DM2 muscle. ${ }^{20-22}$ Thus, the DM2 phenotype may not depend solely on the expression of toxic mutant (CCUG) DM2 $_{\text {tran- }}$ scripts, but may also be due to alterations in ZNF9 expression. Using a large series of patient skeletal muscle biopsies and myoblast cultures, we show here that ZNF9 expression is altered at multiple levels in DM2.

\section{Materials and Methods}

\section{Patient Samples}

Enrollment of patients was approved by the respective local institutional review boards. After obtaining informed consent from the patients, according to the Declaration of Helsinki, muscle biopsies were obtained. The patients and their biopsies used for the different analyses are summarized in Table 1. All DM1 and DM2 diagnoses were based on DNA mutation testing. ${ }^{7,23}$ Muscle biopsies of 11 patients with DM2 were used for immunofluorescence (IF) and Western blotting (WB) studies. In addition to five normal control muscle tissue samples, skeletal muscle biopsies from seven patients with DM1 were used as disease controls. RNA extracted from five DM1 and five DM2 muscle biopsies was used for RT-PCR analysis. Another separate 10 DM1, 20 DM2, and six normal controls were used for microarray expression profiling. ${ }^{24}$ We also performed ZNF9 IF studies on primary myoblast cultures at different time points during differentiation to myotubes.

\section{Microarray Expression Profiling}

\section{Preparation and Labeling of RNA}

Microarray gene expression data are available (NCBI, http://www.ncbi.nlm.nih.gov/geo/, GEO series numbers GSE7014, last accessed on January 28, 2010). ${ }^{24}$ Skeletal muscle biopsies were homogenized by using a shark-tooth pulveriser with TRIzol (Invitrogen, Carlsbad, CA), and total cellular RNA was extracted according to the manufacturer's suggestions. RNA was further purified by using the RNeasy kit (Qiagen, Valencia, $\mathrm{CA}$ ). The quality and integrity of the RNA was analyzed on an Agilent BioAnalyzer by using the RNA 6000 Nano LabChip (Agilent, Santa Clara, CA); samples with a RIN (RNA integrity number) $>7$ were used. For RNA expression profiling on the U133Plus2 GeneChip (Affymetrix, Santa Clara, CA), a total of $5 \mu \mathrm{g}$ of total cellular RNA from each sample was used for CDNA synthesis according to the manufacturer's protocol. Briefly, a mixture of in vitro transcribed CRNAs of cloned bacterial genes for IysA, pheB, thrB, and dap (American Type Culture Collection, Manassas, $V A$ ) was added as external controls to monitor the efficiency of CRNA synthesis. First-strand cDNA synthesis was performed at $42^{\circ} \mathrm{C}$ for 1 hour with the Superscript II system (GIBCO Invitrogen, Carlsbad, CA) at a final concentration of $1 \times$ first-strand synthesis buffer, 10 $\mathrm{mmol} / \mathrm{L}$ dithiothreitol, $500 \mu \mathrm{mol} / \mathrm{L}$ deoxynucleotide triphosphates, $100 \mathrm{pmol}$ of $\mathrm{T} 7-(\mathrm{T})_{24}$ primer, and 200 units of reverse transcriptase. Second-strand cDNA synthesis was performed at $16^{\circ} \mathrm{C}$ for 2 hours at a final concentration of $1 \times$ second-strand buffer, $250 \mu \mathrm{mol} / \mathrm{L}$ dNTP, $65 \mathrm{U} / \mathrm{ml}$ DNA ligase, 250 units/ml DNA polymerase I, and $13 \mathrm{U} / \mathrm{ml} R \mathrm{Nase} \mathrm{H}$. Second-strand synthesis reaction mixtures were cleaned with an Affymetrix cDNA purification column. In vitro transcription labeling with biotinylated UTP and CTP was performed according to the manufacturer's recommendations (Enzo Diagnostics, Plymouth Meeting, PA) for 16 hours at $37^{\circ} \mathrm{C}$. Amplified cRNA was purified on a cRNA purification column (RNeasy, Qiagen), and the quality of the amplification was verified by analysis on an Agilent BioAnalyzer. Labeled cRNAs were fragmented for 35 minutes at $94^{\circ} \mathrm{C}$ in $40 \mathrm{mmol} / \mathrm{L}$ Trisacetate, $\mathrm{pH} \quad 8.1 / 100 \mathrm{mmol} / \mathrm{L} \quad \mathrm{KOAc} / 30 \mathrm{mmol} / \mathrm{L}$ $\mathrm{Mg}(\mathrm{OAc})_{2}$. The hybridization cocktail consisted of $10 \mu \mathrm{g}$ fragmented cRNA in $200 \mu \mathrm{l}$, containing $50 \mathrm{pM}$ control oligonucleotide B2, $0.1 \mathrm{mg} / \mathrm{ml}$ herring sperm DNA, 0.5 $\mathrm{mg} / \mathrm{ml}$ acetylated bovine serum albumin (BSA), 100 $\mathrm{mmol} / \mathrm{L}$ Mes, $20 \mathrm{mmol} / \mathrm{L}$ EDTA, 0.01\% Tween 20 (total $\mathrm{Na}^{+}=1 \mathrm{M}$ ), and bacterial sense cRNA controls for bioB, bioC, bioD, and cre at 1.5, 5.0, 25, and $100 \mathrm{pM}$, respectively. Fragmented cRNAs were then hybridized to Af- 
Table 1. Summary of Muscle Biopsies, Myoblast Cultures, and Analyses Performed

\begin{tabular}{|c|c|c|c|c|}
\hline Samples & Muscle & Age (yr) & Sex & Analysis method \\
\hline $\mathrm{N}-1$ & $G$ & $\sim 50$ & $\mathrm{~F}$ & qPCR \\
\hline $\mathrm{N}-2$ & $\mathrm{H}$ & 73 & $\mathrm{~F}$ & qPCR \\
\hline $\mathrm{N}-3$ & Q & $\sim 50$ & $\mathrm{~F}$ & qPCR \\
\hline $\mathrm{N}-4$ & TA & $\sim 50$ & $\mathrm{~F}$ & qPCR \\
\hline$N-5$ & Q & 60 & $\mathrm{~F}$ & qPCR \\
\hline $\mathrm{N}-6$ & VL & 40 & $\mathrm{M}$ & IF, WB \\
\hline $\mathrm{N}-7$ & VL & 64 & $\mathrm{~F}$ & IF, WB \\
\hline $\mathrm{N}-8$ & VL & 46 & $\mathrm{~F}$ & IF, WB \\
\hline$N-9$ & VL & 24 & M & IF, WB \\
\hline $\mathrm{N}-10$ & $\mathrm{H}(n=3 \mathrm{pool})$ & & $\mathrm{M}, \mathrm{M}, \mathrm{F}$ & IF, WB \\
\hline DM1-1 & TA & 34 & $\mathrm{M}$ & qPCR \\
\hline DM1-2 & TA & 42 & $\mathrm{~F}$ & qPCR, IF, WB \\
\hline DM1-3 & VL & 50 & $\mathrm{M}$ & qPCR, IF, WB \\
\hline DM1-4 & VL & 47 & $\mathrm{~F}$ & qPCR \\
\hline DM1-5 & VL & 46 & M & qPCR, IF, WB \\
\hline DM1-6 & $\mathrm{VL}$ & 34 & M & $\mathrm{IF}, \mathrm{WB}$ \\
\hline DM1-7 & TA & 48 & $\mathrm{M}$ & IF, WB \\
\hline DM1-8 & VL & 39 & $\mathrm{~F}$ & IF, WB \\
\hline DM1-9 & TA & 50 & M & IF, WB \\
\hline DM2-1 & VL & 44 & $\mathrm{M}$ & qPCR \\
\hline DM2-2 & VL & 63 & $\mathrm{~F}$ & qPCR, myocytes \\
\hline DM2-3 & VL & 38 & M & qPCR, IF, WB \\
\hline DM2-4 & VL & 60 & $\mathrm{~F}$ & qPCR \\
\hline DM2-5 & VL & 51 & $\mathrm{M}$ & qPCR \\
\hline DM2-6 & VL & 49 & M & IF, WB, myocytes \\
\hline DM2-7 & $\mathrm{VL}$ & 50 & M & IF, WB \\
\hline DM2-8 & VL & 50 & $\mathrm{~F}$ & IF, WB \\
\hline DM2-9 & VL & 67 & M & IF, WB \\
\hline DM2-10 & $\mathrm{VL}$ & 53 & $\mathrm{M}$ & IF, WB \\
\hline DM2-11 & VL & 60 & $\mathrm{~F}$ & IF, WB, myocytes \\
\hline DM2-12 & VL & 56 & $\mathrm{~F}$ & IF, WB \\
\hline DM2-13 & VL & 62 & M & IF, WB \\
\hline DM2-14 & VL & 56 & $\mathrm{~F}$ & IF, WB \\
\hline DM2-15 & VL & 59 & $\mathrm{~F}$ & IF, WB \\
\hline DM2-16 & VL & 38 & M & IF, WB \\
\hline
\end{tabular}

N, normal control; G, gastrocnemius; H, hip; Q, quadriceps; TA, tibialis anterior; VL, vastus lateralis; F, female; M, male; and qPCR, real-time polymerase chain reaction. IF, immunofluorescence; WB, western blotting.

fymetrix U133Plus2 GeneChips and scanned according to the manufacturer's protocol.

\section{Data Analysis}

Normalization was performed with the Invariant Set Normalization method (PM-only model with DChip default settings) on a normal sample as the reference; DChip model-based expression was applied to calculate the expression values for each probe set. Comparisons between groups were performed, using a fold-change cutoff fold-change $\geq 1.2$, a lower bound limit lower bound $=$ $90 \%$ (default), e-b, b-e difference thresholds of 100 (e = experiment, $b=$ baseline), and a 50-permutations false discovery rate calculation for each comparison. Using U133Plus2 data from DM1 $(n=10)$, DM2 $(n=20)$, and normal adult controls $(n=6)$, we performed global gene expression analysis and then focused on the expression of ZNF9 represented by two probe sets covering the entire gene from exon 1 through exon 5 including the proximal $3^{\prime}$ UTR (206158_s_at) and the distal 3' UTR (227731_at).

\section{Quantitative Real-Time RT-PCR}

To measure the expression levels of ZNF9 mRNA in patients with DM1 and DM2, and normal controls, we per- formed quantitative real-time RT-PCR on five samples in each. DM1 and DM2 samples were matched for age, gender, site of muscle biopsy, and disease stage. Skeletal muscle biopsies were homogenized with Qbiogene FastPrep Homogenizer in Trizol (Invitrogen). The samples were chilled on ice between runs, and RNA was extracted according to manufacturer's instructions. The samples were further purified by using the RNeasy kit (Qiagen). All RNAs were DNasel-treated by using Ambion DNA-free according to the manufacturer's instructions (Applied Biosystems, Inc., Foster City, CA).

RNA amplifications were performed by using RNA Amplification SenseAMP Plus Kit according to the manufacturer's instructions (Genisphere, Inc., Hatfield, PA). To avoid 3' bias, random primers were used. The final amplified RNA produced was in the sense orientation. CDNA produced as a byproduct during the amplification was removed by one or more (if necessary) rounds of treatment with Ambion DNA-free according to the manufacturer's instructions (Applied Biosystems, Inc.). Absence of contaminating genomic DNA was determined by PCR with $\mathrm{S} 15$ primers that amplify a $361-\mathrm{bp}$ band present in genomic and cDNA but not in RNA.

cDNA was synthesized from the amplified RNA by using $250 \mathrm{ng}$ random hexamers and SuperScript II Reverse Transcriptase enzyme according to the manufac- 
Table 2. PCR Primers and Primer Combinations for ZNF9 Splice Variant Analysis

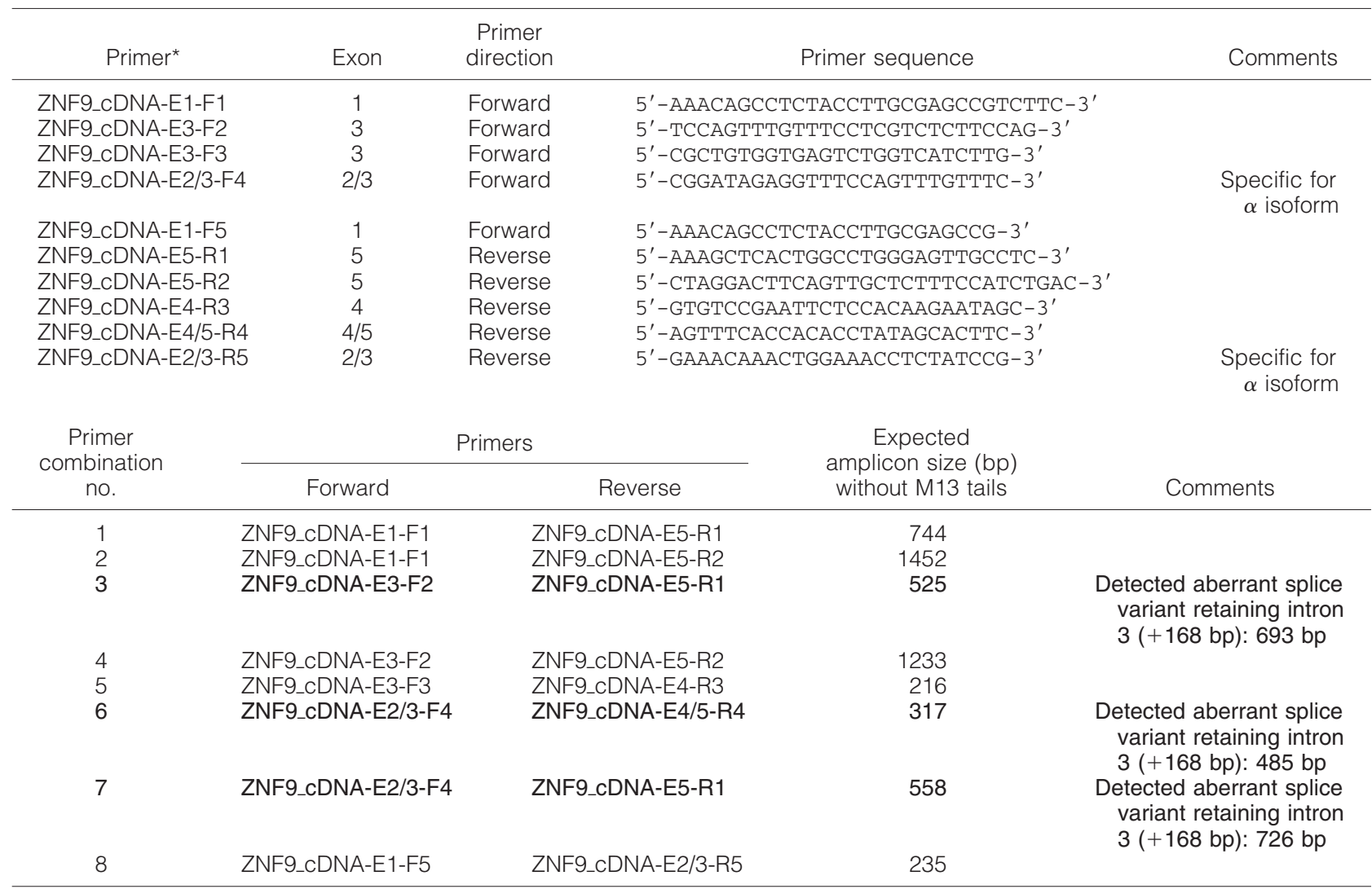

${ }^{*}$ For direct sequencing of PCR products, forward primers were tailed with M13F and reverse primers with M13R. M13F, 5'-TGTAAAACGACGGCCAGT-3'; M13R, 5'-CAGGAAACAGCTATGACC-3'. Bold type indicates the aberrant splice variants.

turers protocol (Invitrogen). RNaseOUT and $\mathrm{RNaseH}$ were not used. cDNA was used for quantitative RT-PCR. Samples were run in triplicate on an Applied Biosystems 7000 Real-Time PCR System. We used TaqMan probes Assay-on-demand gene expression products (ZNF9: Hs00231535 m1; Applied Biosystems, Inc.) covering the exon 1-2 boundary of ZNF9. Normalized TATA box binding protein id Hs99999910 m1 (Applied Biosystems, Inc.) was used as an endogenous control, and probes were compared by using the $\delta$-delta $C_{t}$ method. ${ }^{17}$ The run was repeated with similar results. Results were analyzed for statistical significance by using Mann-Whitney pair wise comparisons of normal versus DM2, DM1 versus DM2, and DM1 versus normal samples, and overall $P$ value using the Kruskal-Wallis test.

\section{Splice Variant and Allele-Specific Transcript Analysis}

\section{cDNA Synthesis}

cDNA from total muscle RNA was generated by using standard methods. Briefly, for each sample $5 \mu \mathrm{g}$ of total RNA were Dnasel-treated (Ambion, Austin, TX) according to the manufacturer's suggestions. cDNA synthesis (SuperScript III First-strand CDNA Synthesis Kit; Invitrogen) was performed on half and half of the Dnasel-treated RNA in separate reactions by using random hexamer and
oligo-(dT) priming according to the manufacturer's protocol. All cDNAs were then RNase $\mathrm{H}$ treated. Equal amounts of random hexamer and oligo-( $\mathrm{dT}$ ) primed cDNA were pooled and diluted to $200 \mu \mathrm{l}$ with molecular grade RNase-free $\mathrm{H}_{2} \mathrm{O}$. cDNAs were tested for genomic contamination by PCR for a known untranscribed genomic marker.

\section{Reverse Transcription-Polymerase Chain Reaction}

Each RT-PCR used $2 \mu$ l of cDNA (12.5 ng RNA-equivalents) in a $20-\mu$ l reaction and was performed for 35 cycles. ZNF9 PCR primers and primer combinations are described in Table 2. Appropriate RT controls were included in all experiments.

\section{Cloning and Sequence Analysis}

M13-tailed PCR products $(5 \mu l)$ were cloned into pCR2. 1 and transformed into Escherichia coli according to the manufacturer's suggestions (Invitrogen Life Technology, Carlsbad, CA). Transformed cells were plated on a single 7-cm Luria-Bertani (LB) agar plate with kanamy$\operatorname{cin}(50 \mu \mathrm{g} / \mathrm{ml})$. After incubation at $37^{\circ} \mathrm{C}$ for 18 hours, 96 single colonies were picked and transferred to a 96-well PCR plate containing LB broth. After an additional incubation at $37^{\circ} \mathrm{C}$ for 2 hours, $5 \mu$ l of each microculture were 
dissolved in $50 \mu \mathrm{l} \mathrm{H}_{2} \mathrm{O}$. Each culture was then PCR amplified by using M13F and M13R primers. Five (5) microliters of each PCR product were analyzed on a $3 \%$ standard Tris-acetate ethylenediamine tetraacetic acid (TAE) agarose gel. Larger than expected amplicons, based on the ZNF9 intron-exon structure, were used for direct sequencing by using the BigDye Terminator version 3.1 Cycle Sequencing Kit according to the manufacturer's protocol (Applied Biosystems, Inc.). The sequencing products were subjected to postsequencing clean-up by ethanol precipitation, containing $3 \mathrm{M}$ NaAcetate (1/10 volume) and $100 \%$ ice-cold ethanol. Products were precipitated by centrifugation at $3000 \mathrm{~g}$ for 30 minutes, washed twice in $70 \%$ ethanol, and dried in a vacuum isotemp oven for 5 minutes. After denaturation in $20 \mu \mathrm{l}$ $\mathrm{Hi}$-Di formamide (Applied Biosystems, Inc.) at $95^{\circ} \mathrm{C}$ for 5 minutes, samples were loaded on a 3100 Genetic Analyzer (Applied Biosystems, Inc.). Sequences were analyzed with Sequencher 4.7 (Gene Codes, Ann Arbor, MI).

\section{Cycloheximide Treatment}

To block nonsense-mediated RNA decay (NMD) of aberrantly spliced transcripts containing a premature termination codon, myoblast cultures at $80 \%$ to $90 \%$ confluency and myotube cultures after 48 hours and 144 hours of differentiation of one patient with DM2, one DMlike patient without DM1 or DM2 mutation, and one normal control were treated with $10 \mu \mathrm{g} / \mathrm{ml}$ cycloheximide (Sigma, St. Louis, MO) for 8 hours before lysis and RNA extraction. Proper inhibition of NMD was determined by monitoring increases in steady-state mRNA levels for ATF3 and GADD45B (which are subject to NMD to regulate mRNA levels), by real-time quantitative RT-PCR using glyceraldehyde-3-phosphate dehydrogenase and $\beta$-actin (ACTB) as internal controls in separate experiments, each performed in triplicate.

\section{Allele-Specific Expression Analysis}

To verify that the abnormal allele of ZNF9 was expressed, skeletal muscle cDNA from patients with DM2 and non-DM2 controls were subjected to repeat primed PCR and capillary electrophoresis as previously described. ${ }^{7}$ Presence of the long 4-bp repeat stutter peaks was considered evidence for expression of the mutant allele at the pre-mRNA level. To determine whether transcription of pre-mRNA occurred from both alleles, we took advantage of single nucleotide polymorphism (SNP) rs1871922, an A/C polymorphism in intron 1 of ZNF9, located $20 \mathrm{bp}$ from the exon-intron junction and identified by the presence of a Haelll restriction site. We used a quantitative allele-specific method that was a modification of the previously reported procedure. ${ }^{7,25}$ Briefly, PCR amplification was carried out in quadruplicate on both cDNA and genomic DNA by using a three primer reaction to incorporate a 5' Fluorescein amidite (FAM) label. After digestion with HaellI, samples were subjected to capillary electrophoresis, and the ratio of the peak heights of the two alleles in heterozygous individuals were used to calculate an allele specific expression index equal to

$$
\begin{aligned}
& {\left[\text { Intensity }\left(\mathrm{A}_{\mathrm{CDNA}}\right) / \text { Intensity }\left(\mathrm{A}_{\mathrm{CDNA}}+\mathrm{C}_{\mathrm{CDNA}}\right)\right]} \\
& \text { /[Intensity } \left.\left(\mathrm{A}_{\text {gDNA }}\right) / \text { Intensity }\left(\mathrm{A}_{\text {gDNA }}+\mathrm{C}_{\mathrm{gDNA}}\right)\right] .
\end{aligned}
$$

The allele specific expression index from two non-DM2 individuals was compared with that of eight DM2 samples by using a two-sample $t$-test comparing normal with DM2 samples.

\section{SDS-Polyacrylamide Gel Electrophoresis and Western Blotting}

Muscle biopsies were treated as previously described for SDS-polyacrylamide gel electrophoresis and Western blotting ${ }^{26}$ After SDS-polyacrylamide gel electrophoresis, proteins were transferred onto polyvinylidene difluoride membrane and immunolabeled with three different rabbit polyclonal antibodies against ZNF9: anti-ZNF9-3268 raised against a 20 -amino acid peptide from the c-terminus of ZNF9 (CYRCGESGHLARECTIEATA) and affinity purified (kind gift from L.T. Timchenko, Baylor College of Medicine, Houston, TX), anti-ZNF9-YPL also raised against the last 20 amino acids of ZNF9, ${ }^{27}$ and a commercial polyclonal anti-ZNF9-A01 raised against full length ZNF9 (Abnova Corporation, Taipei, Taiwan). Antibodies were diluted at 1:5000, 1:1200 and 1:100. Anti- $\beta$ actin antibody C4 (Santa Cruz Biotechnology, Inc., Santa Cruz, CA) diluted 1:200,000 was used to assess protein loads of samples on the same blot. After horseradish peroxidase-conjugated goat anti-rabbit and goat antimouse IgG secondary antibodies (Zymed Laboratories, Inc., San Francisco, CA) at 1:15000 were incubated, the antibody reacting bands were visualized by using an enhanced chemiluminescence detection kit (SuperSignal West femto maximum sensitivity substrate; Pierce Biotechnology, Rockford, IL). Blots were performed in triplicates.

\section{Immunofluorescence}

\section{Muscle Biopsies}

Muscle biopsies were snap-frozen in isopentane cooled with liquid nitrogen. Six-micrometer sections were used for IF studies. Two different polyclonal anti-ZNF9 antibodies were applied: anti-ZNF9-3268 and anti-ZNF9YPL. After blocking of unspecific proteins with 5\% BSA in PBS, sections were incubated with ZNF9-3268 and ZNF9-YPL antibodies diluted $1: 50$ and 1:250, respectively, for 1 hour. After washes, sections were incubated for 1 hour with labeled anti-rabbit IgG (Alexa-fluor 555 and Alexa-fluor 488; Molecular Probes, Inc., Eugene, OR) diluted at 1:500. Sections were washed, counterstained with 4',6-diamidino-2-phenylindole (DAPI), and mounted with a mounting media containing an anti-fading agent. Slides were viewed under an Olympus $1 \times 70$ confocal microscope (Olympus Corporation, Tokyo, Japan).

\section{Myoblast-Myotube Cell Cultures}

Two different normal myoblast cell lines and three DM2 myoblast cell lines were established. Two control myo- 
blast cell lines (17/02 and 588/98) were obtained from Muscle Tissue Culture Collection/EuroBioBank (Munich, Germany). The 17/02 cell line was generated from biceps muscle of a 52-year-old male control subject and the $588 / 98$ cell line from biceps of a 61-year-old female without any pathological findings on histological examination. The origin of the three DM2 cell lines used is indicated in Table 1. The cells were maintained in Skeletal Muscle Cell Growth Medium (PromoCell, Heidelberg, Germany) supplemented with the supplement mix (PromoCell), 10\% fetal bovine serum, Gentamicin (Gibco, Carlsbad, CA), and Gluta-MAX-1 (Gibco) in $5 \% \mathrm{CO}_{2}$ at $37^{\circ} \mathrm{C}$. The cells were differentiated in Dulbecco's modified Eagle's medium containing Gentamicin, Gluta-MAX, and $10 \mu \mathrm{g} / \mathrm{ml}$ insulin (Sigma). At different timepoints of differentiation $(0,3$, and 7 days) cells on glass coverslips were fixed with methanol at $-20^{\circ} \mathrm{C}$ and permeabilized by using $0.2 \%$ triton-X 100 with $0.2 \%$ BSA in PBS. After blocking cells with $0.2 \%$ BSA in PBS, cells were incubated with anti-ZNF9-YPL diluted 1:250 and anti-ZNF9-3268 diluted 1:50 for 80 minutes. After washes, cells were incubated for 1 hour with labeled anti-rabbit IgG (Alexa-fluor 488; Molecular Probes, Inc.) diluted at 1:500. Cells were washed, nuclei counterstained with DAPI, and mounted with a mounting media containing an anti-fading agent. Cells were viewed under a Zeiss Axioplan 2 fluorescent microscope, and an Axiocam digital camera was used to obtain digital images (Carl Zeiss, Göttingen, Germany).

\section{Results}

\section{Aberrant Subcellular Localization of ZNF9 in DM2 Patient Muscles}

On longitudinal sections, cytoplasmic ZNF9 was organized in sarcomeric striations at the Z-disk, in both controls and patient samples (Figure 1, J-L). Moreover, ZNF9 expression levels were higher in slow type 1 fibers, and no localization in the nuclei was observed. IF analysis of ZNF9 in skeletal muscle tissue transverse sections showed somewhat less cytoplasmic and more membrane-bound protein in patients with DM2 compared with normal controls and DM1 disease controls (Figure 1, A-I). However, in the subpopulation of highly atrophic type 2 fibers, characteristic for the muscle pathology in DM2, the expression was intense due to loss of cytoplasm. No cell subtype showed increased expression in DM1 or control samples. Results were identical for the two different antibodies used.

\section{Decreased ZNF9 Protein Levels in Patients with $D M 2$}

On Western blotting ZNF9 protein levels in DM2 muscle samples were reduced compared with DM1 and normal control samples tested with three different antibodies against ZNF9 (Figure 2, A and B). Depending on the antibody used and the epitope detected, reductions in mean protein levels to approximately $15 \%$ to $50 \%$ were

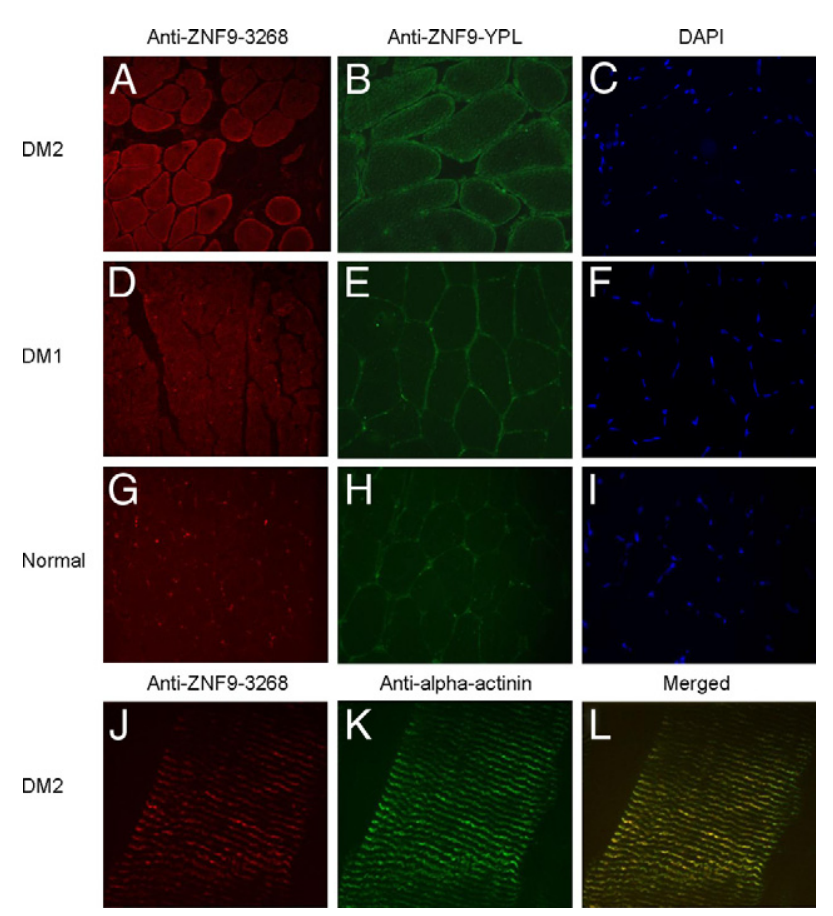

Figure 1. Abnormal subcellular localization of ZNF9 in DM2. In IF analysis, DM2 patient muscle biopsies showed somewhat less cytoplasmic and more membrane-bound ZNF9 protein with anti-ZNF9-3268 antibody (A) compared with DM1 (D) and normal control muscle biopsies (G). Identical results were obtained by using a second ZNF9 antibody, anti-ZNF9-YPL, in DM2 (B), DM1 (E), and normal control (H) muscle biopsies. Corresponding DAPI staining of DM2 (C), DM1 (F), and normal control muscle biopsies (I) is shown. Cytoplasmic localization of ZNF9 was in the sarcomeric striations in the Z-disks (J). Localization at the Z-disks was confirmed by $\alpha$-actinin staining $(\mathbf{K})$, a known Z-disk marker, merged image $(\mathbf{L})$.

observed. In addition to the $\sim 19-k D a$ ZNF9, the antibodies ZNF9-A01 and ZNF9-YPL apparently cross-reacted with an unknown protein of about $\sim 30 \mathrm{kDa}$. Statistical analysis in each group was done by using Mann-Whitney pairwise comparisons with $P<0.001$ in normal versus DM2 with all three antibodies, $P<0.001$ in DM1 versus DM2 with antibodies ZNF9-3268 and ZNF9-YPL, $P=$ 0.002 with the ZNF9-A01 antibody, $P=0.945$ in normal versus DM1 with antibodies ZNF9-3268 and ZNF9-A01, and $P=0.628$ with the antibody ZNF9-YPL. Overall statistical significance was calculated by using the KruskalWallis test with $P \leq 0.001$ for all three antibodies.

\section{Expression of ZNF9 during in Vitro Differentiation}

In contrast to the subcellular cytoplasmic and sarcomeric localization seen in mature muscle, the expression of ZNF9 in early myoblasts (day 0) was markedly perinuclear in addition to the abundant nuclear localization (Figure 3, A-D). By day 3, the perinuclear staining was diminished, whereas nuclear staining was increased (Figure 3, E-H). Some cytoplasmic expression was observed toward the end of differentiation on day 7 (Figure 3, I-L). Both ZNF9-YPL and ZNF9-3268 antibodies gave similar results. However, the ZNF9-3268 antibody showed a slightly stronger perinuclear staining in myoblasts compared with the ZNF9-YPL (data not shown). In 


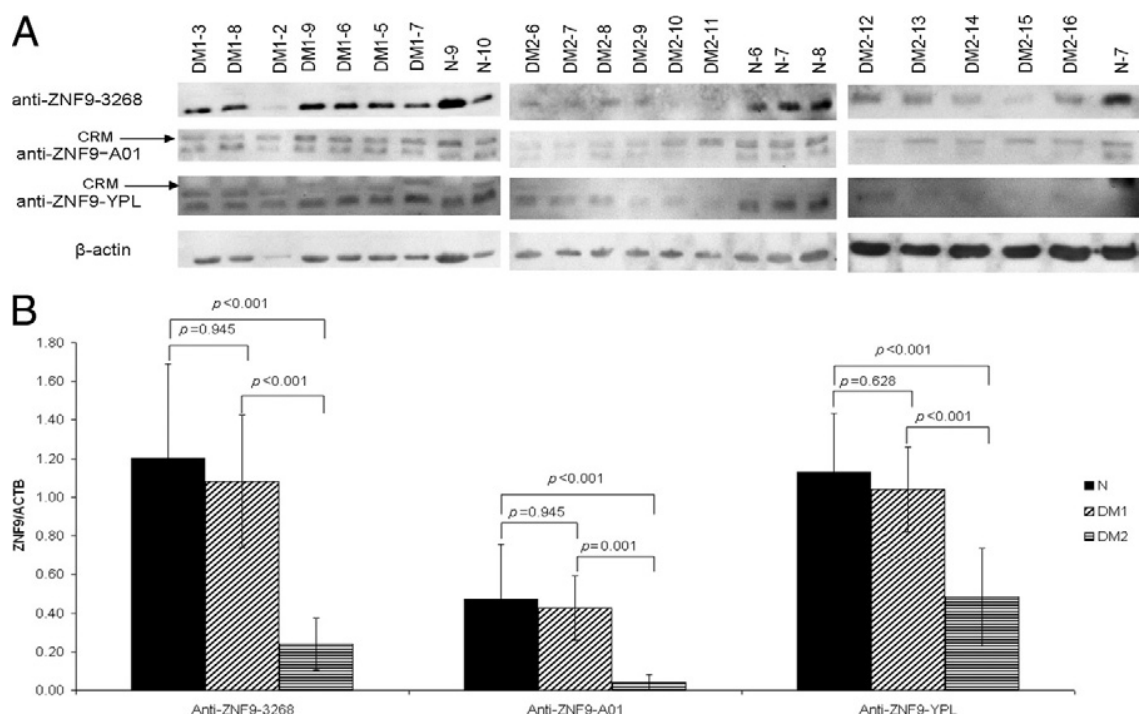

Figure 2. Reduced ZNF9 protein levels in DM2 A: Representative Western blots showing significant reduction of ZNF9 protein levels in DM2 muscle samples compared with DM1 and normal control samples probed with three different antibodies against ZNF9 (see Figure 4A for epitopes detected). CRM, cross-reacting material. B: Bar graphs showing ZNF9 protein expression for normal control, DM1, and DM2 samples. DM2 samples showed statistically highly significant reduction for all three antiZNF9 antibodies.

in vitro myoblast-myotube cultures, no distinct differences in ZNF9 expression were observed between DM2 and control samples.

\section{Decreased ZNF9 mRNA Expression Levels in Patients with DM2}

Consistent with the observed decrease in ZNF9 protein, mRNA expression levels in DM2 muscle samples was also reduced. Global microarray gene expression profiling of DM patient biopsies, including 10 patients with DM1, 20 patients with DM2, and six normal controls, indicated that ZNF9 mRNA levels were consistently lower than those of DM1 and normal individuals (Figure 4, A and B). For the two available ZNF9 probe sets on the U133 Plus2 array, the results were more pronounced for the set covering the distal 3' UTR than the entire coding region and proximal 3' UTR. Follow-up validation experiments by quantitative real-time RT-PCR using a ZNF9specific TaqMan probe (Hs00231535 m1) covering the exon 1-2 boundary of ZNF9 showed that expression was reduced by approximately half in patients with DM2 relative to DM1 and normal control individuals (Figure 4C), whereas no decrease was seen between patients with DM1 and normal controls. Statistical analysis in each group was done by using Mann-Whitney pair wise comparisons with $P=0.009$ in normal versus DM2, $P=0.028$ in DM1 versus DM2, and $P=0.753$ in normal versus DM1. The overall statistical significance was calculated by using the Kruskal-Wallis test with $P=0.02$.

\section{Aberrant Splicing of ZNF9 Pre-mRNA in DM2}

The observed reduction of ZNF9 mRNA levels by approximately $50 \%$ and the protein level down to $15 \%$ to $50 \%$ suggested a direct effect of the DM2 mutation on gene expression and prompted us to investigate ZNF9 transcripts for possible alterations. To this end, we performed qualitative RT-PCR analysis with primers in various combinations in overlapping amplicons, including junction
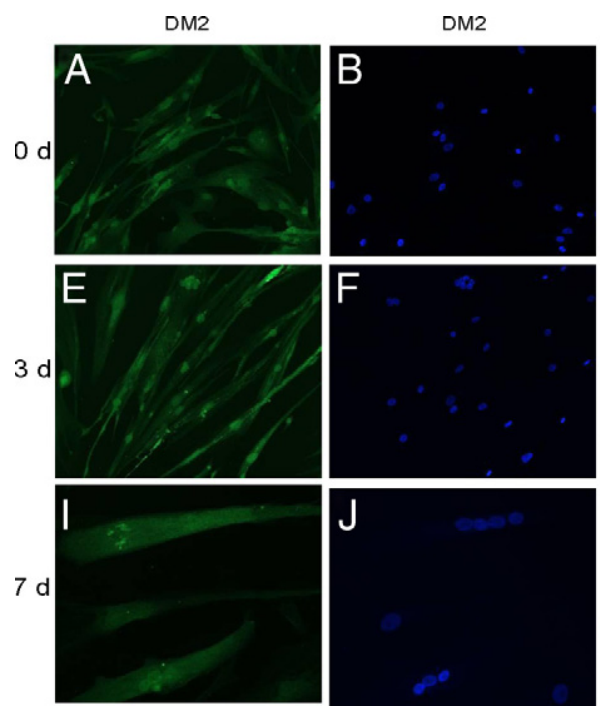

Normal
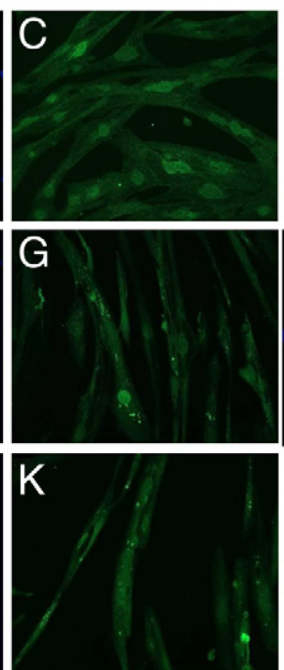

Normal

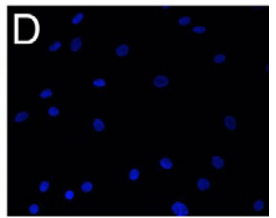

$\mathrm{H}$
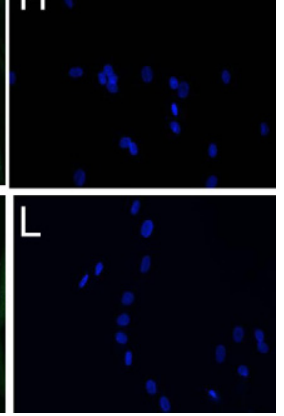

Figure 3. Expression of ZNF9 during in vitro differentiation. During in vitro differentiation, day 0 undifferentiated DM2 (A) and normal (C) myoblast cultures showed nuclear and perinuclear ZNF9 protein expression. At day 3 during early myotube differentiation, ZNF9 protein expression showed less perinuclear and more nuclear staining DM2 (E) and normal $(\mathbf{G})$ cells. At day 7 after induction of myotube differentiation, ZNF9 expression showed more cytoplasmic and less nuclear staining in DM2 (I) and normal cells (K). Corresponding DAPI stainings of DM2 $(\mathbf{B}, \mathbf{F}$ and $\mathbf{J})$ and normal cultures $(\mathbf{D}, \mathbf{H}$, and $\mathbf{L})$, respectively, is shown. Original magnification, $\times 60(\mathbf{A}, \mathbf{B}$ and $\mathbf{E}, \mathbf{F}) ; \times 1000(\mathbf{C}, \mathbf{D}$ and $\mathbf{G}-\mathbf{L})$. 
A

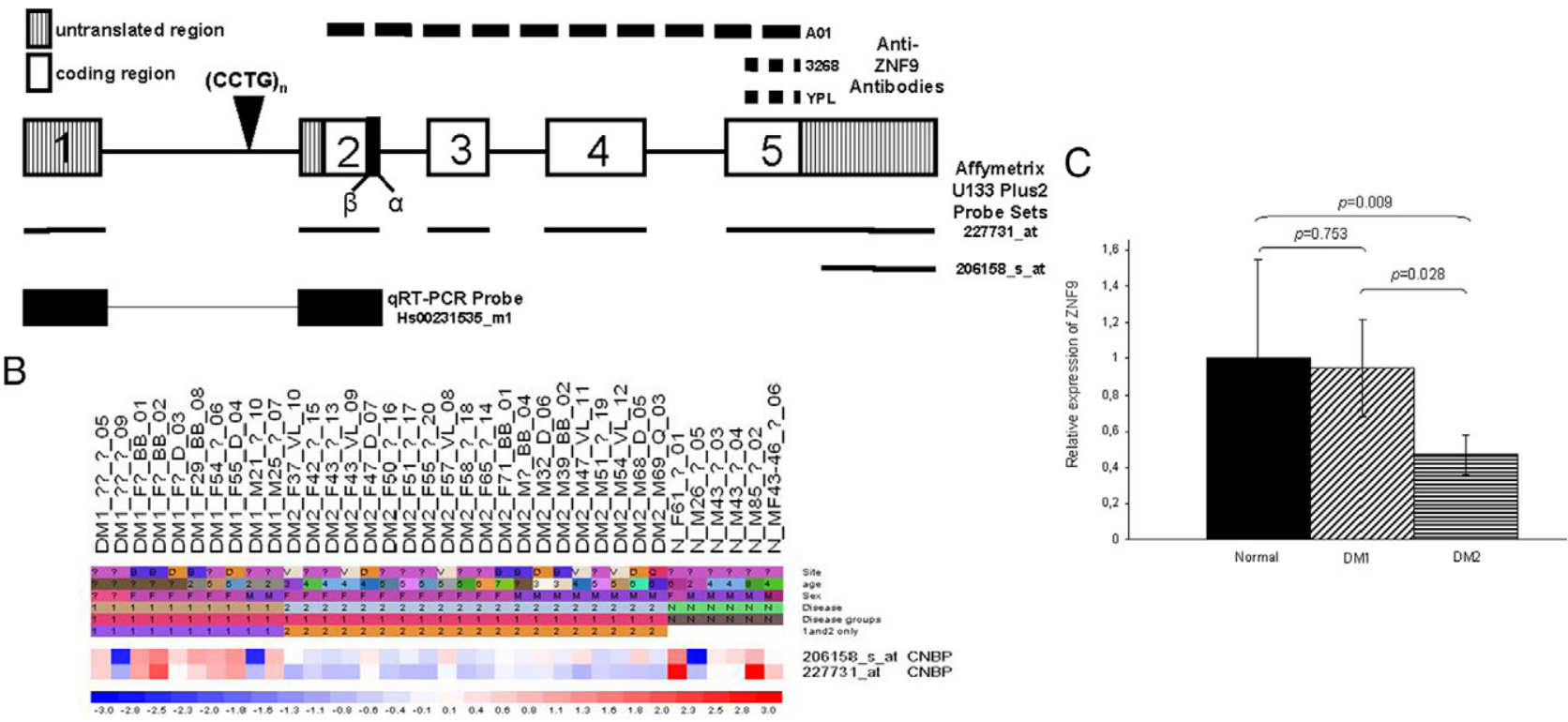

Figure 4. Reduced mRNA expression of ZNF9 in DM2. A: Intron-exon structure of ZNF9. The location of Affymetrix U133 Plus 2 probe sets used in the microarray analysis, the TaqMan probe (Applied Biosystems, Inc.) used for real-time RT-PCR, and the epitopes of the three antibodies used for Western blotting and IF analyses are indicated. Exons and introns are not drawn to scale. Exon 2 has two splice donor sites $(\alpha$ and $\beta)$ and is alternatively spliced to give rise to two isoforms ( $\alpha$, full-length; $\beta,-21 \mathrm{bp} / 7$ amino acids) represented by the black bar. B: Microarray expression profiling of mRNA from skeletal muscle biopsies for ZNF9 (DM1, $n=10 ; \mathrm{DM} 2, n=20$; and $n=6$ ). C: Bar graphs showing results of real-time RT-PCR analysis of total ZNF9 mRNA (DM1, $n=5 ;$ DM2, $n=5 ;$ and $n=5$ ). Microarray expression profiling and real-time RT-PCR analysis of samples from patients with DM2 showed overall significantly reduced total mRNA levels compared with patients with DM1 and normal control individuals. Overall $P$ value $=0.02$.

primers spanning exons 2/3 (forward) and exons 4/5 (reverse; Figure 5, A and B; Table 2). Two different amplicons covering exon 3 to exon 5 consistently detected a novel fragment in patients with DM2, whereas no other
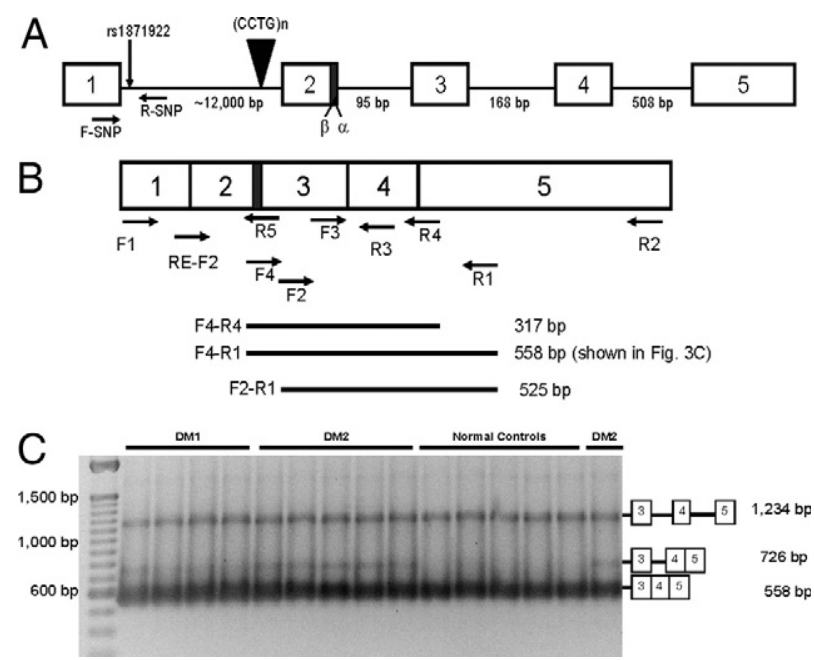

Figure 5. Splice variant analysis of ZNF9 in DM2. A: Intron-exon structure of ZNF9. Exons and introns are not drawn to scale; intron sizes in bp and primers used for SNP analysis are shown. ZNF9 is spliced to give rise to two isoforms ( $\alpha$, full-length; $\beta,-21 \mathrm{bp} / 7$ amino acids) represented by the black bar. Exon 2 has two splice donor sites. B: Structure of mature ZNF9 mRNA showing locations of primers used for RT-PCR analyses. The aberrantly retained intron 3 (168 bp) was originally identified by using exonic primers F2 and R1. Primer combinations F4-R4 and F4-R1 also amplified fragments containing the aberrantly retained intron 3. The presence of the retained intron was verified by sequencing. C: Splice variant analysis of ZNF9 identified a novel fragment of 726 bp only seen in biopsies of patients with DM2 due to the aberrant retention of intron 3. The aberrant fragment shown was generated using RT-PCR primer F4, which spans an exon/intron junction, and R1. region of the transcript showed evidence of abnormal splicing (Figure $5 \mathrm{C}$ ). Based on the observed size of the variant product and the intron-exon structure of ZNF9, we suspected the retention of intron 3 . Sequence analysis of cloned amplicons revealed that the novel fragment was indeed the result of intron 3 retention. Retention of intron 3 gives rise to a novel open reading frame extending 22 codons into intron 3 before terminating with a premature termination codon (PTC).

To estimate the abundance of intron 3 retaining transcripts, we cloned the entire RT-PCR reaction product from different patients with DM and normal control individuals. Analysis of at least 100 individual colonies from each sample established that variant products were present at low frequency of about 10\% in DM2 and $\leq 3 \%$ in DM1 and not present in normal control samples.

We first assumed the abnormal splice variant was derived from the mutant allele and that its very low expression was due to NMD of the PTC transcript. However, experiments blocking NMD with cycloheximide failed to increase the abundance of abnormal transcript (data not shown), suggesting that NMD was not responsible for the decrease in steady-state levels of ZNF9 mRNA.

\section{Allele-Specific Expression of ZNF9}

To verify that both alleles of ZNF9 were expressed, skeletal muscle cDNA from patients with DM2 and non-DM2 controls was subjected to repeat primed PCR and capillary electrophoresis. Repeat primed-PCR of the DM2 repeat revealed a characteristic pattern of peaks which, for a normal allele, consists of at least two clusters of 

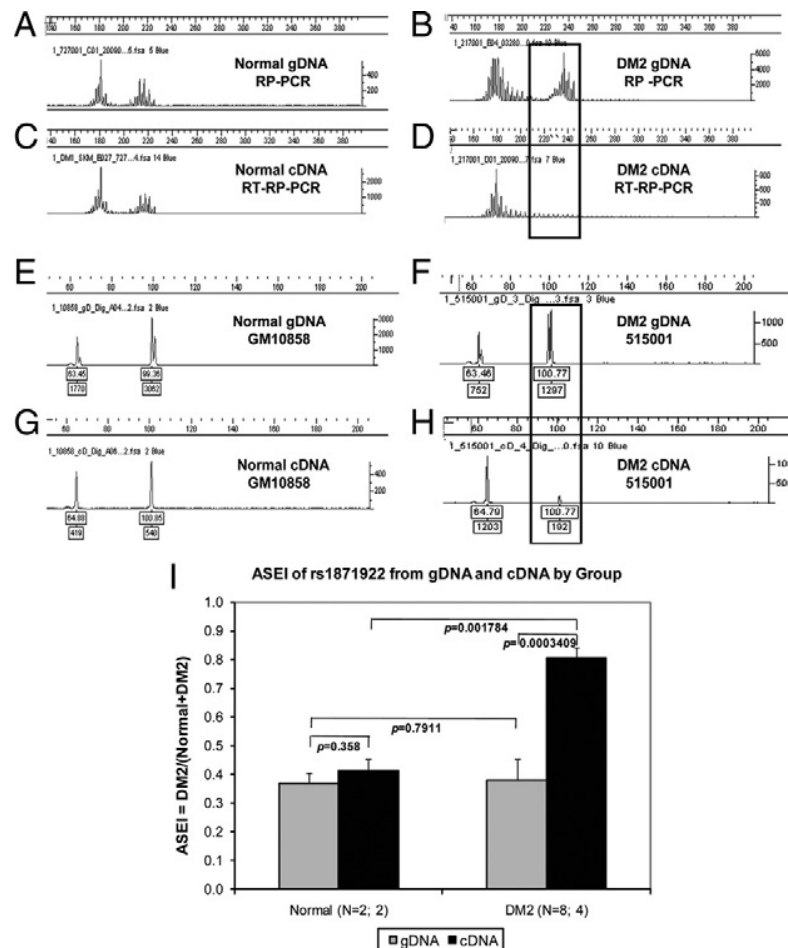

Figure 6. Allele-specific processing defect in DM2. A-D: Representative electropherograms of DM2 and wild-type alleles using repeat-primed (RP) PCR with a reverse primer of the sequence $5^{\prime}-(\mathrm{CAGG})_{5}-3^{\prime}$. $\mathbf{A}$ and $\mathbf{C}$ are from a normal individual, B and $\mathbf{D}$ from a patients with DM2. A and $\mathbf{B}$ show amplification from genomic DNA, $\mathbf{C}$ and $\mathbf{D}$ from cDNA. In normal individuals, the gDNA and cDNA products (A and $\mathbf{C}$ ) are essentially identical, showing amplification of both alleles. In patients with DM2, amplification of both alleles (similar to that seen in normals) was observed at the gDNA, whereas at the cDNA level no amplification of the wild-type allele was observed (box; B and D). E-H: Representative electropherograms of DM2 and wild-type alleles using the SNP rs1871922 detected by HaeIII digestion. The 64-bp peak represents the $\mathrm{C}$ allele, which is in absolute linkage disequilibrium with the DM2 mutant expansion, and the 101-bp peak represents the wild-type A allele. $\mathbf{E}$ and $\mathbf{G}$ are from a normal individual, $\mathbf{F}$ and $\mathbf{H}$ from a patient with DM2. E and $\mathbf{F}$ show amplification from gDNA, $\mathbf{G}$ and $\mathbf{H}$ from cDNA. In normal individuals, the gDNA and cDNA are essentially identical, showing amplification of both alleles. In patients with DM2, the product from the mutant $C$ allele is markedly increased relative to wild-type A. I: Summary of allele-specific expression analysis showing an approximate greater than twofold increase in DM2 pre-mRNA allele levels (ASEI, allele-specific expression index), indicating a mutant pre-mRNA processing defect. Corresponding gDNA results with no differences are shown for comparison. $N=\mathrm{x}$; y: x, number of gDNA samples; $y$, number of cDNA samples in each group. Each gDNA and cDNA sample was analyzed as four replicates. Using the cDNA/ gDNA ratios, a two-sample $t$-test comparing normals with patients with DM2 gave a highly significant $P=0.0003409$.

peaks separated by one or more 4 to 12 bp interruptions. For the expanded DM2 allele, a single group of repeats is followed by stutter peaks at 4-bp intervals, which gradually taper off in intensity. In genomic DNA, where both alleles are present in equal amounts, these two patterns are superimposed, and the presence or absence of the mutant allele is easily discerned (Figure 6, A and B). When this assay was conducted by using cDNA, normal individuals displayed a pattern essentially identical to that of their matching genomic DNA (Figure 6C) indicating that transcripts of the two alleles are present at approximately equal amounts. In patients with DM2, however, we observed a signal characteristic of the expansion allele with no evidence of the peaks characteristic of the corresponding normal allele (Figure 6D).
This was surprising, as it seemed to suggest that the normal allele was selectively silenced, an occurrence that would be highly unlikely. However, the repeat sequence being assayed is present in pre-mRNA only, and is normally spliced out from the processed message and degraded. A more likely interpretation of the result is that the pre-mRNA transcribed from the mutant allele is not degraded, but accumulates in the nucleus, an interpretation consistent with the presence of nuclear foci in DM2 cells. Because it accumulates, there would be multiple copies of the mutant (CCUG) $)_{\mathrm{DM} 2}$ RNAs present while the normal allele is degraded, thus explaining the apparent absence of the normal allele in this assay.

To determine whether the overall reduction in ZNF9 mRNA reflected expression of only one allele, we took advantage of SNP rs1871922 in intron 1 near the exon 1 boundary. This sequence is approximately $12 \mathrm{~kb}$ removed from the mutant repeat and is expected to be present only in the pre-mRNA. The $\mathrm{C}$ allele is in absolute linkage disequilibrium with the DM2 expansion in patients with DM2. ${ }^{7}$ We performed quantitative genotyping of this SNP on both genomic DNA and cDNA of DM2 and nonDM2 skeletal muscle from patients heterozygous for this SNP. In normal individuals, the relative signal from the A and $C$ alleles was the same in cDNA (Figure 6E) as it was in genomic DNA (Figure 6G), indicating equal expression of both alleles. However, this was not the case in DM2 muscle, where the signal from the $C(D M 2)$ allele was considerably higher than that from the $A$ (wild type) allele (Figure 6, $\mathrm{F}$ and $\mathrm{H}$ ). Calculation of allele-specific premRNA expression indices showed that the amount of DM2-associated allele, relative to total expression, was increased more than twofold in DM2 samples (Figure 6l; $P=0.0003409$ DM2 versus normal), suggesting a processing defect of the mutant pre-mRNA due to the presence of the (CCUG) DM2 $_{2}$ expansion in intron 1 as the cause for the overall reduction in total ZNF9 mRNA levels.

\section{Discussion}

Although DM1 and DM2 share many phenotypic features, there are clear differences between these two diseases, which cannot easily be explained by identical molecular pathomechanisms caused by toxicity of their mutant RNAs and secondary splicing abnormalities. Clinical symptoms such as myotonia are much more inconsistent in DM2 than in adult-onset DM1 even if the CLCN1 splice abnormality is at least as pronounced in DM2 as in DM1. Moreover, DM2 does not show a congenital form of the disease, and severe central nervous system involvement is not part of the DM2 phenotype. DM2 is also characterized by proximal muscle weakness and a subpopulation of extremely small type 2 fibers on muscle biopsies, in contrast to the distal weakness and atrophy with moderate type 1 fiber atrophy in DM1. These clinical differences could be explained by different temporal and spatial expression patterns of dystrophia myotonica protein kinase and ZNF9, the genes harboring the repeat mutations. Moreover, effects on and of the resident genes may also account for certain aspects of the overall phenotype. This 
has been demonstrated by the use of knockout mouse models for dystrophia myotonica protein kinase and ZNF9 ${ }^{19,28}$ both of which have phenotypic aspects of DM. Moreover, reduction of ZNF9 protein levels has been demonstrated in myoblasts from patients with DM2. ${ }^{22}$ Here we showed that ZNF9 expression is altered at multiple levels, including total mRNA and protein expression as well as subcellular localization. Exploring the mechanism of reduced ZNF9 expression, we detected evidence for failure to properly process the pre-mRNA of the mutant allele, accounting for the overall decrease of transcript and protein.

We observed that in patients with DM2, intron 3 of ZNF9 was aberrantly retained, which gives rise to mutant transcripts encoding a mutant open reading frame with a PTC in intron 3. The predicted mutant protein would only contain the first two of seven zinc-knuckles found in the normal ZNF9 protein and would likely be nonfunctional. However, given that the PTC occurs in intron 3 close to the amino terminus (the ATG translational start site is in exon 2) and is followed by an additional intron, we hypothesized that intron 3-retaining, aberrantly spliced mutant RNAs are subject to NMD and that no aberrant proteins are actually produced. ${ }^{29}$ However, blocking NMD did not cause any increase of the abnormal transcript and therefore NMD does not appear a plausible mechanism to account for the observed reduction in steady-state ZNF9 mRNA and protein levels. We next hypothesized that the retention of intron 3 may be indicative of a more generalized splicing or processing defect of ZNF9 pre-mRNA. Using allele-specific transcript quantification of the mutant and wild-type alleles taking advantage of an intron 1 SNP, we observed that a polymorphic sequence from the $5^{\prime}$ end of intron 1 of the mutant allele, along with the expanded repeat, is preferentially retained compared with the normal allele. This persistence of multiple intron 1 sequences from the mutant allele, when considered with the presence of incompletely spliced intron 3 , suggests that splicing of the mutant allele is impaired at multiple levels. This processing failure could account for the overall reduction ( $50 \%)$ of $\mathrm{mRNA}$ and protein that we observed. It is not possible from these experiments to determine whether the entire mutant premRNA is retained or only partially spliced messages. However, our detection of the retained intron 3 in fragments obtained by using primers that cross exon boundaries suggests the latter. Whether these partially spliced messages are entirely contained in the foci or whether they are present in soluble fractions remains to be determined.

Our findings are consistent with recent reports of reduced ZNF9 expression in DM2 22,30 and provide the first molecular mechanism for the observed reduction. Our results also help to explain the observation that ZNF9 heterozygous knockout mice in the absence of toxic $(\mathrm{CCUG})_{\mathrm{DM} 2}$ transcripts exhibit a number of DM2 features, ${ }^{19}$ where reduction of ZNF9 levels in heterozygous $\mathrm{Znfg}^{+/-}$knockout mice has been shown to be sufficient to produce multiorgan symptoms resembling those of DM, including myotonia, muscular dystrophy, and cardiac defects. Taken together with our findings of reduced mRNA and protein levels in patients with DM2, it is likely that ZNF9 haploinsufficiency accounts for some of the DM2specific manifestations. That the reduction in mRNA and protein levels was previously not detected ${ }^{17,18}$ may be due to a number of reasons. First, a limited number of immortalized lymphoblastoid cell lines ${ }^{17}$ may not be the appropriate cell type to detect the aberrant expression that we observed in skeletal muscle biopsies, the tissue primarily affected in patients with DM2. Similarly, examination of only myoblast cultures from one heterozygous and one homozygous patient with DM2 may be insufficient to detect quantitative differences. ${ }^{18}$ By their design, these previous studies focused only on the exon $1 / 2$ junction and not downstream introns of ZNF9 such as we examined, nor could they identify allele-specific effects. Using a more quantitative approach (quantitative RT$\mathrm{PCR}$ ) on DM2 patient biopsies rather than myoblast cultures, we determined that ZNF9 mRNA was significantly reduced compared with non-DM2 individuals, including patients with DM1. Using somatic cell hybrids containing a human chromosome with a mutant DM2 allele as well as homozygous DM2 myoblasts, Margolis et al ${ }^{18}$ were able to amplify by RT-PCR mRNA containing properly spliced exons 1 and 2. This is not inconsistent with our finding of excess intron 1 pre-mRNA originating from the mutant allele. Some normal splicing may certainly occur and can be detected by RT-PCR. However, we propose that in a significant proportion of the pre-mRNA intron 1 is not spliced out. Our experiments do not address the presence or absence of the remainder of intron 1, only that region close to the splice junction where a polymorphism permits distinction between mutant and wild-type alleles.

Based on the collective data, we propose that for DM2 mutant ZNF9 pre-mRNA transcripts, as exons 1 and 2 are brought into close proximity in preparation for splicing, there is steric interference due to the expanded $(C C \cup G)_{D M 2}$ repeat. As a result, splicing is retarded or may fail entirely for the majority of transcripts, accounting for the increased steady-state levels of premRNA from the mutant allele, whereas the overall processed message is reduced. Most of intron 1 may be degraded normally, but the region close to the splice junction may be protected by its proximity to the expansion during splicing and may or may not end up in the foci. The presence of a small percentage of transcripts that retain intron 3 is consistent with overall retarded mRNA processing. In addition to reduced ZNF9 mRNA and protein levels, we observed a difference in subcellular localization with less cytoplasmic and more membrane-bound protein in DM2 muscle. These localization changes apparently take place only after maturation of muscle tissue.

ZNF9 has been reported to function as a DNA- and RNA-binding protein with alternatively spliced isoforms modulating $\beta$-myosin heavy chain gene expression. ${ }^{31-35}$ This is consistent with our findings in normal controls, where overall ZNF9 expression is higher in slow type 1 fibers than in fast type 2 fibers and early differentiating myocytes (data not shown). However, the localization of ZNF9 changing from the nuclei in undifferentiated myoblasts to the cytoplasm during differentiation to myotubes 
and the cytoplasmic localization of ZNF9 in mature human muscle fibers in sarcomeric striations at the Z-disks ${ }^{36}$ is unexpected for a transcription factor and suggestive of other functions in mature muscle fibers. In fact, ZNF9 has recently been implicated in the regulation of cap-dependent and -independent translation. ${ }^{35}$ In this context, our finding of reduced overall and especially cytoplasmic ZNF9 levels in mature DM2 muscle may be significant. In conclusion, we identified clear differences in ZNF9 expression between patients with DM1 and DM2. The observed clinical manifestations in patients with DM1 and DM2 may thus be due to a combination of shared (nuclear pathology due to toxic RNA) and separate (cytoplasmic pathology due to, at least in part, ZNF9) pathomechanisms accounting for overlapping as well as distinct features.

\section{Acknowledgments}

We are grateful to the participating patients for their cooperation. The microarray expression profiling study has been accomplished through the active collaboration and sharing of patient samples within the European Neuromuscular Centre consortium on DM2 and Other Myotonic Dystrophies by the following members: Josep Gamez, Jerry Mendell, Guillaume Bassez, Bruno Eymard, and Tetsuo Ashizawa. DM1 patient samples were also provided by Lars Edström (Karolinska Institute, Stockholm, Sweden). We thank Jaana Leppikangas, Satu Luhtasela, Henna-Riikka Koskinen, Helena Luque, Valerie L. Neubauer, Tamara J. Nixon, and Tamer Ahmed for their expert technical assistance, and Keith Baggerly for statistical assistance. We also thank the Muscle Tissue Culture Collection for providing two of the control myoblast cell lines. Muscle Tissue Culture Collection is part of the German network on muscular dystrophies (MD-NET, service structure S1, 01GM0601) funded by the German ministry of education and research (BMBF, Bonn, Germany). The Muscle Tissue Culture Collection is a partner of EuroBioBank and TREAT-NMD.

\section{References}

1. Harper PS: Myotonic Dystrophy. London, Saunders, 1989, pp 1-384

2. Udd B, Meola G, Krahe R, Thornton C, Ranum LP, Bassez G, Kress W, Schoser B, Moxley R: 140th ENMC International Workshop: myotonic dystrophy DM2/PROMM and other myotonic dystrophies with guidelines on management. Neuromuscul Disord 2006, 16:403-413

3. Brook JD, McCurrach ME, Harley HG, Buckler AJ, Church D, Aburatani H, Hunter K, Stanton VP, Thirion JP, Hudson T: Molecular basis of myotonic dystrophy: expansion of a trinucleotide (CTG) repeat at the $3^{\prime}$ end of a transcript encoding a protein kinase family member. Cell 1992, 68:799-808

4. Fu YH, Pizzuti A, Fenwick RG, Jr, King J, Rajnarayan S, Dunne PW, Dubel J, Nasser GA, Ashizawa T, de Jong P: An unstable triplet repeat in a gene related to myotonic muscular dystrophy. Science 1992, 255:1256-1258

5. Mahadevan M, Tsilfidis C, Sabourin L, Shutler G, Amemiya C, Jansen G, Neville C, Narang M, Barcelo J, O'Hoy K: Myotonic dystrophy mutation: an unstable CTG repeat in the $3^{\prime}$ untranslated region of the gene. Science 1992, 255:1253-1255

6. Liquori CL, Ricker K, Moseley ML, Jacobsen JF, Kress W, Naylor SL,
Day JW, Ranum LP: Myotonic dystrophy type 2 caused by a CCTG expansion in intron 1 of ZNF9. Science 2001, 293:864-867

7. Bachinski LL, Udd B, Meola G, Sansone V, Bassez G, Eymard B Thornton CA, Moxley RT, Harper PS, Rogers MT, Jurkat-Rott K, Lehmann-Horn F, Wieser T, Gamez J, Navarro C, Bottani A, Kohler A, Shriver MD, Sallinen R, Wessman M, Zhang S, Wright FA, Krahe R: Confirmation of the type 2 myotonic dystrophy (CCTG)n expansion mutation in patients with proximal myotonic myopathy/proximal myotonic dystrophy of different European origins: a single shared haplotype indicates an ancestral founder effect. Am J Hum Genet 2003, 73:835-848

8. Bachinski LL, Czernuszewicz T, Ramagli LS, Suominen T, Shriver MD, Udd B, Siciliano MJ, Krahe R: Premutation allele pool in myotonic dystrophy type 2. Neurology 2009, 72:490-497

9. Udd B, Krahe R, Wallgren-Pettersson C, Falck B, Kalimo H: Proxima myotonic dystrophy: a family with autosomal dominant muscular dystrophy, cataracts, hearing loss and hypogonadism; heterogeneity of proximal myotonic syndromes? Neuromuscul Disord 1997, 7:217-228

10. Udd B, Meola G, Krahe R, Thornton C, Ranum L, Day J, Bassez G, Ricker K: Report of the 115th ENMC workshop: DM2/PROMM and other myotonic dystrophies; 3rd Workshop, 14-16 February 2003; Naarden, The Netherlands. Neuromuscul Disord 2003, 13:589-596

11. Vihola A, Bassez G, Meola G, Zhang S, Haapasalo H, Paetau A, Mancinelli E, Rouche A, Hogrel JY, Laforet P, Maisonobe T, Pellissier JF, Krahe R, Eymard B, Udd B: Histopathological differences of myotonic dystrophy type 1 (DM1) and PROMM/DM2. Neurology 2003, 60:1854-1857

12. Schoser BG, Schneider-Gold C, Kress W, Goebel HH, Reilich P, Koch MC, Pongratz DE, Toyka KV, Lochmuller H, Ricker K: Muscle pathology in 57 patients with myotonic dystrophy type 2. Muscle Nerve 2004, 29:275-281

13. Timchenko LT, Miller JW, Timchenko NA, DeVore DR, Datar KV, Lin L, Roberts R, Caskey CT, Swanson MS: Identification of a (CUG)n triplet repeat RNA-binding protein and its expression in myotonic dystrophy. Nucleic Acids Res 1996, 24:4407-4414

14. Osborne RJ, Thornton CA: RNA-dominant diseases. Hum Mol Genet 2006, 15 Spec No 2:R162-R169

15. Ho TH, Savkur RS, Poulos MG, Mancini MA, Swanson MS, Cooper TA: Colocalization of muscleblind with RNA foci is separable from misregulation of alternative splicing in myotonic dystrophy. J Cell Sci 2005, 118:2923-2933

16. Wang J, Pegoraro E, Menegazzo E, Gennarelli M, Hoop RC, Angelini C, Hoffman EP: Myotonic dystrophy: evidence for a possible dominant-negative RNA mutation. Hum Mol Genet 1995, 4:599-606

17. Botta A, Caldarola S, Vallo L, Bonifazi E, Fruci D, Gullotta F, Massa R, Novelli G, Loreni F: Effect of the [CCTG]n repeat expansion on ZNF9 expression in myotonic dystrophy type II (DM2). Biochim Biophys Acta 2006, 1762:329-334

18. Margolis JM, Schoser BG, Moseley ML, Day JW, Ranum LP: DM2 intronic expansions: evidence for CCUG accumulation without flanking sequence or effects on ZNF9 mRNA processing or protein expression. Hum Mol Genet 2006, 15:1808-1815

19. Chen W, Wang Y, Abe Y, Cheney L, Udd B, Li YP: Haploinsuffciency for Znf9 in Znf9+/- mice is associated with multiorgan abnormalities resembling myotonic dystrophy. J Mol Biol 2007, 368:8-17

20. Gerbasi VR, Link AJ: The myotonic dystrophy type 2 protein ZNF9 is part of an ITAF complex that promotes cap-independent translation. Mol Cell Proteomics 2007, 6:1049-1058

21. Salisbury E, Schoser B, Schneider-Gold C, Wang GL, Huichalaf C, Jin B, Sirito M, Sarkar P, Krahe R, Timchenko NA, Timchenko LT: Expression of RNA CCUG repeats dysregulates translation and degradation of proteins in myotonic dystrophy 2 patients. Am J Pathol 2009, $175: 748-762$

22. Huichalaf C, Schoser B, Schneider-Gold C, Jin B, Sarkar P, Timchenko L: Reduction of the rate of protein translation in patients with myotonic dystrophy 2. J Neurosci 2009, 29:9042-9049

23. Sallinen R, Vihola A, Bachinski LL, Huoponen K, Haapasalo H, Hackman P, Zhang S, Sirito M, Kalimo H, Meola G, Horelli-Kuitunen N, Wessman M, Krahe R, Udd B: New methods for molecular diagnosis and demonstration of the (CCTG)n mutation in myotonic dystrophy type 2 (DM2). Neuromuscul Disord 2004, 14:274-283

24. Vihola A, Bachinski LL, Sirito M, Olufemi SE, Hajibashi S, Baggerly $K A$, Raheem $O$, Haapasalo $H$, Suominen $T$, Holmlund-Hampf $J$, Paetau A, Cardani R, Meola G, Kalimo H, Edstrom L, Krahe R, Udd B: 
Differences in aberrant expression and splicing of sarcomeric proteins in the myotonic dystrophies DM1 and DM2. Acta Neuropathol 2010, 119:465-479

25. Krahe R, Ashizawa T, Abbruzzese C, Roeder E, Carango P, Giacanelli M, Funanage VL, Siciliano MJ: Effect of myotonic dystrophy trinucleotide repeat expansion on DMPK transcription and processing. Genomics 1995, 28:1-14

26. Haravuori H, Vihola A, Straub V, Auranen M, Richard I, Marchand S, Voit T, Labeit S, Somer H, Peltonen L, Beckmann JS, Udd B: Secondary calpain3 deficiency in 2q-linked muscular dystrophy: titin is the candidate gene. Neurology 2001, 56:869-877

27. Chen W, Liang Y, Deng W, Shimizu K, Ashique AM, Li E, Li YP: The zinc-finger protein CNBP is required for forebrain formation in the mouse. Development 2003, 130:1367-1379

28. Reddy S, Smith DB, Rich MM, Leferovich JM, Reilly P, Davis BM, Tran $\mathrm{K}$, Rayburn H, Bronson R, Cros D, Balice-Gordon RJ, Housman D: Mice lacking the myotonic dystrophy protein kinase develop a late onset progressive myopathy. Nat Genet 1996, 13:325-335

29. Brogna S, Wen J: Nonsense-mediated mRNA decay (NMD) mechanisms. Nat Struct Mol Biol 2009, 16:107-113

30. Pelletier R, Hamel F, Beaulieu D, Patry L, Haineault C, Tarnopolsky M, Schoser B, Puymirat J: Absence of a differentiation defect in muscle satellite cells from DM2 patients. Neurobiol Dis 2009, 36:181-190
31. Rajavashisth TB, Taylor AK, Andalibi A, Svenson KL, Lusis AJ: Identification of a zinc finger protein that binds to the sterol regulatory element. Science 1989, 245:640-643

32. Warden CH, Krisans SK, Purcell-Huynh D, Leete LM, Daluiski A, Diep A, Taylor BA, Lusis AJ: Mouse cellular nucleic acid binding proteins: a highly conserved family identified by genetic mapping and sequencing. Genomics 1994, 24:14-19

33. Yasuda J, Mashiyama S, Makino R, Ohyama S, Sekiya T, Hayashi K Cloning and characterization of rat cellular nucleic acid binding protein (CNBP) cDNA. DNA Res 1995, 2:45-49

34. Flink IL, Morkin E: Alternatively processed isoforms of cellular nucleic acid-binding protein interact with a suppressor region of the human beta-myosin heavy chain gene. J Biol Chem 1995, 270:6959-6965

35. Pellizzoni L, Lotti F, Maras B, Pierandrei-Amaldi P: Cellular nucleic acid binding protein binds a conserved region of the $5^{\prime}$ UTR of Xenopus laevis ribosomal protein mRNAs. J Mol Biol 1997, 267:264-275

36. Massa R, Panico MB, Caldarola S, Fusco FR, Sabatelli P, Terracciano C, Botta A, Novelli G, Bernardi G, Loreni F: The myotonic dystrophy type 2 (DM2) gene product zinc finger protein 9 (ZNF9) is associated with sarcomeres and normally localized in DM2 patients' muscles. Neuropathol Appl Neurobiol 2010, 36:275-284 